\title{
EXPERIÊNCIAS OUTRAS NA UTILIZAÇÃO DAS TICS COMO INTERFACE PEDAGÓGICA NA ESCOLA DE EDUCAÇÃO DE JOVENS E ADULTOS
}

\author{
Amilton Alves de Souza (UNEB)* \\ Antonio Quintas-Mendes (UAP)** \\ Alfredo Eurico Rodrigues Matta (UNEB)***
}

\section{RESUMO}

Este estudo trata das "Experiências outras na utilização das TIC como interface pedagógica na escola de Educação de Jovens e Adultos". Como objetivo geral da pesquisa, propomos analisar como a utilização das TIC como interface pedagógica contribui com os sujeitos da EJA. Apresentamos como problema da pesquisa a busca de resposta para a seguinte questão: Como utilizar as tecnologias da informação e da comunicação como interface pedagógica para os sujeitos da EJA? Os objetivos específicos são: Investigar as experiências de aprendizagens dos estudantes no laboratório de informática; refletir epistemologicamente os conceitos de Letramentos, TIC e EJA; identificar que projetos contribuem como interface pedagógica para melhoria da aprendizagem. A abordagem de pesquisa adotada. Foi a qualitativa, de natureza descritivo-analítica, com instrumentalização do estudo de caso e a efetivação de um conjunto de entrevistas semiestruturadas e análise documental. Os resultados destacam as possibilidades dos sujeitos da EJA de buscar novas formas de utilizar as TICs, no processo de ensino-aprendizagem, a efetivação das rodas de conversas, dos temas geradores como fundantes do empoderamento e da construção do conhecimento dos sujeitos. Concluímos que à escola deva repensar seu tempo, espaço e as experiências de ensinar e aprender, da formação continuada dos professores, da criação de um museu

* Doutorando pela Universidade Federal da Bahia. Mestre em Educação de Jovens e Adultos, pela Universidade do Estado da Bahia. Coordenador Educativo e Cultural da Rede Municipal de Ensino de Araçás/ BA. Grupo de Pesquisa em Gestão, Organização, Tecnologia e Políticas Públicas em Educação (GP-GEPE) e Grupo de Pesquisa em: Sociedade em Rede e Pluriculturalidade - aplicações pluriculturais e plurilinguisticas da tecnologia Digital e em Rede. E-mail: amiltonalvess@hotmail.com

** Doutorado em Educação pela Universidade Aberta. Professor do Departamento de Educação a Distância da Universidade Aberta de Portugal. E-mail: quintasmendes@gmail.com

*** Pós-doutor em Educação a Distância pela Universidade do Porto, Portugal. Pesquisador do CNPQ. Professor do DMMDC e PPGEDUC da Universidade do Estado da Bahia (UNEB). Grupo de Pesquisa em: Sociedade em Rede e Pluriculturalidade - aplicações pluriculturais e plurilinguisticas da tecnologia Digital e em Rede. E-mail: alfredomatta@gmail.com. 
virtual de aprendizagem e da construção de práticas dialógicas permanentes no âmbito da escola da EJA.

Palavras-Chave: Educação de Jovens e Adultos. Letramentos. Tecnologia da Informação e da Comunicação.

\section{ABSTRACT \\ OTHER EXPERIENCES IN THE USE OF CT AS A PEDAGOGICAL INTERFACE IN THE SCHOOL OF EDUCATION OF YOUNG PEOPLE AND ADULTS}

This study deals with the "Other experiences in the use of TIC as a pedagogical interface in the school of Education of Youth and Adults". As a general objective of the research, we propose to analyze how the use of TIC as a pedagogical interface contributes with the subjects of EJA. We present as a research problem the search for answers to the following question: How to use information and communication technologies as pedagogical interface for the subjects of EJA? The specific objectives are: to investigate students' learning experiences in the computer lab; to reflect epistemologically the concepts of literacy, TIC and EJA; identify which projects contribute as pedagogical interface for learning improvement. The approach adopted was qualitative, descriptive-analytical in nature, with instrumentalization of the case study and the execution of a set of semi-structured interviews and documentary analysis. The results highlight the possibilities of the subjects of EJA to seek new ways to use TIC, in the teaching-learning process, the implementation of conversation wheels, of the generating themes as foundations of the empowerment and construction of the knowledge of the subjects. We conclude that the school should rethink its time, space and experiences of teaching and learning, of the continuing training of teachers, the creation of a virtual learning museum and the construction of permanent dialogical practices within the EJA school.

Keywords: Youth and Adult Education. Literature. Information and Communication Technology.

\section{RESUMEN}

\section{OTRAS EXPERIENCIAS EN EL USO DE TC COMO INTERFAZ PEDAGÓGICA EN LA ESCUELA DE EDUCACIÓN DE JÓVENES Y ADULTOS}

Este estudio se ocupa de las experiencias en el uso de las TIC como interfaz pedagógica en la escuela de Educación de Jóvenes y Adultos". Como objetivo general de la investigación, proponemos analizar cómo el uso de las TIC como interfaz pedagógica contribuye con los sujetos de la EJA. Presentamos como problema de la investigación la búsqueda de respuesta a la siguiente pregunta: ¿Cómo utilizar las tecnologías de la información y de la comunicación como interfaz pedagógica para los sujetos de la EJA? Los objetivos específicos son: Investigar las experiencias de aprendizaje de los estudiantes en el laboratorio de informática; reflejar epistemológicamente los conceptos de 
Letramentos, TIC y EJA; identificar qué proyectos contribuyen como interfaz pedagógica para la mejora del aprendizaje. El enfoque de investigación adoptado Fue la cualitativa, de naturaleza descriptivo-analítica, con instrumentalización del estudio de caso y la realización de un conjunto de entrevistas semiestructuradas y análisis documental. Los resultados destacan las posibilidades de los sujetos de EJA de buscar nuevas formas de utilizar las TIC, en el proceso de enseñanza-aprendizaje, la efectividad de las ruedas de conversación, de los temas generadores como fundantes del empoderamiento y de la construcción del conocimiento de los sujetos. Concluimos que la escuela debe repensar su tiempo, espacio y las experiencias de enseñar y aprender, de la formación continuada de los profesores, la creación de un museo virtual de aprendizaje y la construcción de prácticas dialógicas permanentes en el marco de la escuela de la EJA.

Palabras clave: Educación de Jóvenes y Adultos. Letramentos. Tecnología de la Información y la Comunicación.

\section{Introdução}

Este artigo analisa a questão das "Experiências outras na utilização das TIC como interface pedagógica na escola de Educação de Jovens e Adultos". Como objetivo geral da pesquisa, propomos analisar como a utilização das TIC como interface pedagógica contribui com os sujeitos da EJA. Apresentamos como problema da pesquisa a busca de resposta para a seguinte questão: Como utilizar as tecnologias da informação e da comunicação como interface pedagógica para os sujeitos da EJA? Os objetivos específicos são: Investigar as experiências de aprendizagens dos estudantes no laboratório de informática; refletir epistemologicamente os conceitos de Letramentos, TIC e EJA; identificar que projetos contribuem como interface pedagógica para melhoria da aprendizagem.

Entendemos que a Educação de Jovens e Adultos (EJA) faz parte do processo global de formação popular, bem como da escolarização. Por isso, ao pensarmos na EJA, temos a necessidade de refletir sobre a pluralidade e diversidade de saberes que os estudantes e os professores têm em função dos trabalhos que realizam ou que estão por fazer, em suas práticas de quem ensina e de quem aprende. Neste sentido, quando os sujeitos jovens e adultos vão à busca de ressignificar suas experiências de escolarização, certamente buscam primeiramente o seu desenvolvimento pessoal e profissional. Mas, é necessário perceber que, em qualquer processo educativo, os jovens e adultos devem ter suas iniciativas no saber sensível, porque é através dele que o estudante se abre para o conhecimento reflexivo e dialógico. Entendemos que o grande sentido da EJA deva ser o de uma educação continuada, viabilizadora de processos educativos para os seus sujeitos que, por inúmeros fatores sociais, econômicos e políticos, foram negados principalmente no campo da construção, aquisição e da produção do conhecimento científico - indispensável à condição humana -, assim como dos outros direitos universais.

Assim, a finalidade maior deste estudo é contribuir para que o estudante que cursa a modalidade de EJA, no município de Araçás - Bahia usufrua de uma prática pedagógica ressignificada do professor e com o propósito de formar pessoas conscientes do seu 
papel de cidadão e sujeito de direitos da leitura, escrita e tecnologias na EJA como instrumentos de empoderamento.

É necessário analisar a utilização das Tecnologias da Informação e da Comunicação (TIC) como interface pedagógica na construção de saberes, nas práticas de letramentos, no laboratório de informática, no ambiente escolar. A partir do exposto, para reflexão, apresentamos como problema da pesquisa a busca de resposta para a seguinte questão: como a experiências comas tecnologias da informação e da comunicação como interface pedagógica pode influenciar na leitura e escrita dos sujeitos da EJA?

0 espaço investigado foi a Escola que neste trabalho receberá o codinome de Escola Municipal Lév. A referida unidade de ensino apresentou desafios e inúmeras demandas da EJA. Analisamos como a utilização das TIC como interface pedagógica contribui com os sujeitos da EJA. Neste sentido, podemos estabelecer relações entre as TIC e as práticas de letramentos promovidas pelos sujeitos da EJA, na referida instituição de ensino. Outras proposições são as influências das interfaces pedagógicas na interação e na colaboração das práticas de letramentos e se vêm efetivando a melhoria da qualidade da educação da EJA, pois é fundante compreender como os estudantes da EJA estão sendo mediados na construção do conhecimento para a utilização do laboratório de informática. Por tanto, compreendemos que há possibilidades do uso das tecnologias na construção de saberes, na Escola Municipal Lév, no Município de Araçás-Bahia.

0 artigo está estruturado por esta introdução onde abordamos a problemática e seus objetivos. Em seguida, estabelecemos os procedimentos metodológicos da investigação, destacamos que se trata de uma pesquisa qualitativa. Trazemos a reflexão acer- ca da temática e analisamos as contribuições dos principais autores. Eles apontam caminhos e provocações para discutirmos as concepções e histórico da EJA, a exemplo, Freire (1983; 1987; 1993; 1997) e Gadotti (2007), Rojo (2012) e outros. E, analisamos e discutimos as informações da pesquisa de campo, enfatizamos os saberes, a importância das TIC e a melhoria nas práticas de letramentos, chegando às considerações finais da investigação.

\section{EXPERIÊNCIAS METODOLÓGICAS}

A escolha metodológica foi pela pesquisa qualitativa porque esta modalidade investigativa apresenta uma possibilidade de compreensão da realidade, pois “[...] pesquiso para constatar, constatando intervenho, intervindo educo e me educo. Pesquiso para conhecer o que ainda não conheço e comunicar ou anunciar a novidade". (FREIRE, 1997, p. 32). Não podemos negar a transformação que a educação tem perpassado e requer de nós pesquisadores, novas possibilidades de pensar e produzir conhecimento e demanda das pesquisas, respostas para essa realidade.

Conforme Lüdke e André (1986), o espaço pesquisado nos deu uma gama de possibilidades. Isso porque tivemos um compromisso fidedigno com o nosso campo de pesquisa. Acreditamos que foi fundamental mergulhar neste espaço, pois bebemos, exclusivamente, nessa fonte do saber, na possibilidade de não somente buscar informações, mas, darmos o retorno social que uma pesquisa da EJA merece.

Desse modo, a nossa opção foi por um estudo de caso único: "Experiências outras na utilização das TIC como interface pedagógica na escola de Educação de Jovens e Adultos". Como estratégias de trabalho usaram a pesquisa de campo por entender que, in- 
dependente das diversas complexidades, é fundamental um rigor metodológico e científico a serem experimentados e os pesquisadores devem ter a leveza e tranquilidade durante suas experiências com e no campo. Com uma curiosidade aguçada e inquieta, exploramos, através das entrevistas e observações participantes, como também por meio do diário de saberes, as impressões da fala e corpo do sujeito.

Os sujeitos da pesquisa foram alunos do nível $V\left(8^{\circ}\right.$ e $9^{\circ}$ ano $)$ que frequentavam a Escola Municipal Lév no turno noturno, no ano de 2018 e apresentavam idades entre 18 a 79 anos. A justificativa dos estudantes para retorno à escola são as mais diversas, desde aprender a ler e escrever até a atender uma exigência do mercado de trabalho. $\mathrm{Na}$ sua maioria, eram moradores do campo e viviam da produção agrícola. Outros alunos eram trabalhadores das empresas privadas do ramo do petróleo, mineração e extração de arvores, e o restante, divide-se entre domésticas, trabalhadores do comércio local e moradores da periferia.

Também, fizeram parte como sujeitos da pesquisa, os professores que lecionaram no nível V da escola. Cumpre citar algumas técnicas e instrumentos importantes em uma pesquisa quali, com instrumentalização da pesquisa de campo: entrevista e a observação. Não podemos esquecer que a observação é uma técnica empírica e tem que ser acompanhada por uma revisão teórica. Essa técnica vai requerer de nós, pesquisadores, um rigor científico, envolvimento e um cuidado com a pesquisa na coleta e na análise das informações. Na fase de pesquisa de campo, utilizamos a entrevista semiestruturada que teve o propósito de coletar informações para essa segunda etapa da pesquisa na qual foram realizadas entrevistas com os sujeitos da EJA da Escola Municipal Lév, a saber: alunos que frequentaram ano letivo de 2018, do nível V e docentes escolares.

A entrevista seguiu os roteiros semiestruturados, com a finalidade de coletar informações acerca da melhoria dos alunos na leitura e escrita através das tecnologias, assim como, verificamos qual tipo de metodologia era utilizada no laboratório. 0 objetivo foi de contribuir com a construção de novos saberes na superação da leitura e escrita. Foi elaborado um roteiro denominado de Apêndice A, com doze questões para os alunos e Apêndice B, para os professores. Procuramos observar que a estratégia é ter a consciência de que os instrumentos utilizados podem ou não ser úteis (YIN, 2010). A estratégia geral nos ajuda a construir diversas conclusões analíticas e afastar interpretações infundadas.

Por fim, esperamos que a triangulação das informações pudesse ter dado conta de responder à pergunta fundante deste estudo que propõe, com a pesquisa, contribuir com a escola participante, no sentido de sugerir proposições de melhoria do ensino e da aprendizagem em letramentos por meio das TIC.

\section{COMPREENSÃO CONCEITUAL DA EDUCAÇÃO DE JOVENS E ADULTOS (EJA)}

Iniciamos a compreensão teórica e as experiências da Educação de Jovens e Adultos, a fim de entendemos que a EJA pode ser compreendida como prática educativa que deve reconhecer e validar os saberes e experiências dos sujeitos, do meio e da luta popular, que por questões históricas, culturais e sociais tiveram o direito à educação negada, em algum momento das suas vidas, tendo como movimento essencial, neste processo educativo, a dialética da tomada de conscientização política e a criticidade 
do que se ensina e aprende nas práticas educativas.

A Educação de Jovens e Adultos (EJA) experienciada na escolarização ainda hoje é carregada de negação de diretos, nos mais diversos: currículo, tempo, espaço, formação docente etc. Apesar da legislação atual que asseguram a sua oferta, conforme observaremos a seguir, ainda existem experiências de escolarização que nega essa garantia.

É possível perceber que Educação de Jovens e Adultos não se encarrega somente dos processos de escolarização, mas também a práticas educativas não formais, da luta popular, da relação com o mundo do trabalho, das experiências de letramentos, além de proporcionar, uma compreensão e luta social e política de forma crítica e reflexiva, por meio da dialogicidade e conscientização.

Para Freire (1983) é um dos principais pensadores do século XX para construção teórico/prática da EJA no Brasil e no mundo. Mediador da experiência de emancipação do sujeito que carregam as negações de direitos como condição da opressão, o autor defendia um ensino que pudesse dar conta da conscientização política e do rompimento com a condição de oprimido.

0 autor acima nos possibilita compreender a as práticas de ensina e aprender precisam ser carreadas de um amor que de conta de superar as marcas do desamor, da desumanização pela tomada de consciência e da reflexão permanente a prática dos sujeitos no mundo. A escolarização na EJA bem como suas práticas educativas tanto no campo dos letramentos ou das TIC precisam possibilitar aos sujeitos uma construção do conhecimento que dê conta da ressignificação da autoestima e confiança de oportunidades igualitárias para uma humanização crítica e dialógica.
A tomada pela conscientização pode se dá dentro e fora das práticas de escolarização, é bom lembrar que a EJA como uma prática educativa tem o seu fazer garantido no art. 205 da Constituição Federal de 1988, pois, "a educação, direito de todos e dever do Estado e da família, será promovida e incentivada com a colaboração da sociedade, visando ao pleno desenvolvimento da pessoa, seu preparo para o exercício da cidadania e sua qualificação para o trabalho". Assim, garantir aos sujeitos da EJA, que ao longo das suas histórias de vida tiveram seus direitos negados, possa acessar saberes escolares, principalmente no campo dos letramentos e das TIC é garantir oportunidade cidadã de um sujeito integral nas suas experiências sociais.

A identidade escolar da Educação de Jovens e Adultos se estabelece a partir organização curricular, pois os tempos e os espaços de ensinar e aprender deve ter um desenho curricular flexível, numa articulação entre os saberes de mundo com os saberes sistematizados. Souza (2015, p.54) na sua dissertação "Círculos de Diálogos e Práticas de Letramentos com as TIC: Saberes, Fazeres e Interfaces com a EJA;

A Educação de Adultos é entendida como práticas educativas que reconhecem e validam os saberes e experiências dos homens e mulheres do meio e da luta popular que por questões históricas, culturais e sociais tiveram seus direitos a educação negados em algum momento das suas vidas, tendo como movimento essencial neste processo educativo, a dialética tomada de conscientização política e a criticidade do que se ensina e aprende nas práticas educativas.

Logo, EJA só atende verdadeiramente os seus objetivos se dialogar com os saberes e fazeres do mundo do trabalho. Consideremos a seguir, as TIC e Letramentos como instrumentos de qualificação das experiên- 
cias desses sujeitos jovens e adultos, na ressignificação das práticas educativas através de reflexão crítica.

\section{TIC, ESCOLA, LETRAMENTOS E EXPERIÊNCIAS NA UTILIZAÇÃO DO LABORATÓRIO DE INFORMÁTICAS}

Os últimos vinte anos têm sido pautados pelo crescente desenvolvimento das tecnologias e das transformações sociais que temos experimentado. Como consequência, este desenvolvimento impacta diretamente na relação com o trabalho, mercado, cultura e educação. Logo, a escola não pode continuar distante dessa demanda ao construir de forma bem superficial o histórico da introdução das tecnologias nas escolas do Brasil, a partir da década de 60, tomamos por base o texto de Leite et al. (2012). Neste período, o país resolve incluir nas unidades de ensino as produções tecnológicas das nossas indústrias, pois no fundo o único objetivo era tornar o país um grande produtor e consumidor de bens e passar a ser incluso no mercado mundial, acreditando com isso que teríamos aí a fórmula para a resolução de todos os problemas sociais e as tecnologias seriam visualizadas como determinantes das mudanças pedagógicas das nossas escolas.

Está posto que as TIC são promissoras nestas quebras de paradigmas que apresentamos aqui, pois elas têm possibilitado, ao longo dos últimos anos, professores e alunos a revisarem seus papéis. Gadotti nos convida a refletir esses paradigmas quando trata das tecnologias e as suas implicações na EJA ressaltando que:

Paulo Freire, há 50 anos, já alertava para esse equívoco [...] hoje isso é ainda mais grave: com o desenvolvimento das novas linguagens e novas tecnologias (celular, computador, TV, vídeos, a internet, as diversas mídias e redes sociais...) há uma nova cultura popular de uso intensivo da comunicação. Os alunos sentem-se desconfortáveis com um currículo centrado no domínio da cultura letrada, não levando em consideração o quanto as novas Tecnologias de Comunicação são necessárias não só na vida diária (pagar uma conta, usar um caixa eletrônico...) mas também no trabalho e no exercício da cidadania (2014, p. 21).

Nessa perspectiva, as TIC na sala de aula precisam provocar não só mudanças de paradigmas, mas provocar a escola a repensar seus currículos e a sua prática ao introduzir as TIC nas aulas, como também relacionando as mesmas com o dia a dia que os seus sujeitos têm fora dos muros da escola.

O Plano Nacional da Educação de 2001 nos convocou a pensar sobre a necessidade que a EJA tem de incorporar, no seu fazer pedagógico, as habilidades e competências contemporâneas construídas com o advento das TIC, onde:

A necessidade de contínuo desenvolvimento de capacidades e competências para enfrentar essas transformações alterou a concepção tradicional de EJA, não mais restrita a um período particular da vida ou a uma finalidade circunscrita. Desenvolve-se o conceito de educação ao longo de toda a vida, que há de se iniciar com a alfabetização. Mas não basta ensinar a ler e a escrever. Para inserir a população no exercício pleno da cidadania, melhorar sua qualidade de vida e de fruição do tempo livre e ampliar suas oportunidades no mercado de trabalho, a EJA deve compreender no mínimo, a oferta de uma formação equivalente às oito séries iniciais do ensino fundamental (BRASIL, 2001, p. 99).

As tecnologias na sala de aula não podem continuar a se resumir ao quadro e piloto ou mais recentemente ao datashow, mas precisamos buscar todas as possibilidades de construir uma aprendizagem de interação por meio das tecnologias, valorizando o 
que o aluno já sabe. Realmente não dá mais para pensarmos que na EJA ensinar a ler e a escrever somente dará conta de emponderar socialmente os alunos, a sala de aula que precisa estar atenta a essa nova demanda tecnológica construída e experimentada na vida social. 0 fato destes novos aparatos tecnológicos não estarem disponíveis nas nossas escolas, faz com que os educadores tenham a obrigação de provocar espaços de diálogos sobre o uso e acesso a essas tecnologias que fazem parte das relações e construções dos sujeitos.

É importante pensar para além da TIC, outras tecnologias utilizadas ou trabalhadas no espaço escolar a exemplo de jogos, atividades culturais, experiências com a produção de materiais manipuláveis e produtos caseiros. Precisamos entender que o simples fato de trabalhar com tecnologias, na sala de aula não garantem a qualidade e um ensino promissor. Para Rebêlo (2005, p. 1), “[...] incluir digitalmente não é apenas 'alfabetizar' a pessoa em informática, mas também melhorar os quadros sociais a partir do manuseio dos computadores", sendo assim, as tecnologias precisam ocupar um espaço de inclusão, propiciando a nossos sujeitos utilizá-las para potencializar a criticidade da sua realidade, podendo construir novas formas de se ver e perceber o mundo da informação e comunicação.

Diante do exposto, percebe-se que a escola não tem outra saída a não ser refazer alguns caminhos didáticos e metodológicos, mas para isso é preciso discutir com seus pares uma nova concepção de escola e de sujeitos, as suas demandas por meio das TIC e ressignificar seu currículo, PPP, e a formação de seus atores curriculantes. Com isso, possibilitará conceber outras formas de ensinar e aprender que precisa ser para ontem, pois o sujeito da EJA, assim como to- dos os sujeitos em suas fases da vida, é nato à disposição para aprender, porém essa disposição de aprender só acontece se essa aprendizagem for significativa.

Percebemos que a articulação entre leitura, escrita e TIC, precisa se constituir como um caminho didático que carrega finalidades educativas e que conjectura dos envolvidos uma adaptação e ressignificação das práticas conservadoras em ensinar e aprender, bem como em ler e escrever. Neste sentido, os caminhos didáticos disponíveis que nem sempre foram criados para este fim, não podem jamais se constituir para um fim em si mesmo, mas um meio de aprender.

Diante da citação exposta acima percebemos que a autora nos convida a refletir sobre o uso das TIC nas aulas, pois precisam dar um salto na qualidade e na melhoria do ensino. As TIC não podem ser mais um caminho nas mãos dos professores que não refletem mudanças na prática docente.

A informática aqui será tratada como informática educativa que tem por objetivo o uso e desenvolvimento da informação para fins educativos no intuito de possibilitar aos sujeitos um conhecimento ampliado das TIC. Vale salientar que não defendemos um ensino de informática na escola, mas que a informática possa contribuir na melhoria da aprendizagem, especificamente na leitura e escrita, permeando pelas mais diversas disciplinas por meio do laboratório de informática, a fim de que os alunos possam reescrever suas leituras e escritas na dinâmica que os computadores possibilitam.

\section{SABERES E SIGNIFICADOS DAS TIC NOS LETRAMENTOS PARA EJA}

Então, Letramento ou Letramentos? Como se constituem letramentos, multiletramentos, letramentos múltiplos, letramentos crí- 
ticos? Quais as contribuições para escola e as TIC por meio dos letramentos e multiletramentos? Ao tentarmos construir alguns movimentos que poderão indicar alternativas ou possibilidades de compreensão das inquietações acima, optamos politicamente por tecer uma discussão teórica sobre letramentos e TIC.

Letramento ou Letramentos? A questão aqui não é de escolha, mas de compreensão do que se aproxima da nossa discussão proposta. No entanto, precisamos entender a partir de Rojo (2009) que define como "letramento" as experiências sociais que têm como instrumento a linguagem por meio do movimento da leitura e escrita, nos mais diversos espaços sociais. Varia sempre de espaço e tempo por meio das culturas nas suas adversidades e diversidades. Nesta perspectiva, "letramentos" são as experiências sociais das mais diversas e plurais linguagens tendo a informação e comunicação como movimentos que ressignificam a leitura e a escrita. Neste sentido, fica evidente que letramentos definem e configuram melhor nossa discussão teórica e crenças políticas defendidas nas construções conceituais do referido texto. Logo, justifica-se a posição por letramentos, pois as transformações culturais, históricas e sociais, mas principalmente da própria cultura tecnológica e digitais, mudaram a nossa possibilidade e sentido de ler e escrever.

Neste contexto, os movimentos construídos pelas experimentações sociais (relações com os saberes culturais, históricos, econômicos e educacionais) dos sujeitos da EJA carregam consigo uma heterogeneidade de polissemia de sentidos e relações, principalmente em nossa contemporaneidade, onde as mudanças da sociedade têm ocorrido de forma veloz, devido à chamada era das TIC digitais, que tem mudando nossa forma de acessar e construir a informação e comunicação, assim sendo podemos denominar de "letramentos múltiplos" como denomina Rojo (2009). Embora tenhamos todas essas experimentações sociais ocorrendo, nossas escolas e currículos insistem em negar e ignorar as experiências de letramentos múltiplos que nossos sujeitos vivenciam em suas práticas com e no mundo. Há notoriamente uma negação de direito quanto à valorização dos saberes populares constituídos de letramentos.

No caso específico das tecnologias da informação e comunicação digitais essa negação é pior por não reconhecer os novos aparatos e mídias tecnológicas utilizadas pelos sujeitos em seus espaços e tempo, a exemplo das redes sociais, whatsapp, e-mails, salas de bate papo, músicas. As práticas da maioria das escolas são de ensinar somente reprodução do conhecimento, códigos escritos e reprodução da leitura, nossa afirmativa não é infundada, mas é fruto de diversas pesquisas e estudos no país e academias. A escola como instituição social precisa se preparar para não negar as experimentações sociais, fruto da nossa cultura de massa carregada de diversidade e letramentos.

O Multiletramento é constituído a partir das diversas práticas e produções letradas das multiculturas e linguagens, inclusive de mídias. Todos os sujeitos que compõe a escola contribuem com estas práticas de multiletramentos na escola, a partir de suas experimentações culturais, socioculturais e multiculturais tendo o respeito às diferenças culturais como base de suas práticas. Neste sentido, os multiletramentos vão requerer sempre as mais diversas possibilidades de escrita, e leitura, e novas interfaces pedagógicas, a exemplo de aparatos tecnológicos, mídias, linguagens (hipermídias e 
hipertextos) que deverão ajudar as novas experimentações de saberes como as ressignificações, criticidades, problematização, diálogos e produções. Conforme Rojo (2012), os multiletramentos possuem características próprias como a interatividade; rompem todas as relações, quebrando com a hegemonia; são híbridos.

Partimos da compreensão de que a polissemia de sentidos que carrega os multiletramentos na escola, principalmente a que oferta a modalidade de educação de jovens e adultos, precisa compreenderem estes movimentos que as TIC exercem na vida de seus sujeitos e possibilitam revolucionar a prática docente e os espaços de aprendizagem dentro da unidade de ensino, transformando a forma de aprender e ensinar. Os multiletramentos rompem com a negação de direito e de acesso na sala de aula com as TIC, não cabe mais pedir ao sujeito para guardar a caixinha de som nem o celular, mas juntos docentes e discentes ressignificam os espaços e tempos, podendo ser um momento significativo, pois quem ensina aprende e quem aprende ensina.

Outro aspecto interessante a ser observado na prática dos multiletramentos é que a escola ainda não sabe lidar com as diversas possibilidades textuais disponíveis em nossas experimentações sociais e nem propicia aos alunos o encontro com os hipertextos e hipermídias. Portanto, urgentemente, docentes e gestores precisam investir exponencialmente em qualificação, formação, capacitação, ensejando trabalhar com os mais diversos gêneros textuais tendo como suporte às tecnologias digitais com intuito de contribuir como interface pedagógica para melhorar a leitura e escrita dos alunos.

Por fim, as instituições de ensino precisam compreender e assegurar que suas propostas pedagógicas devem possibilitar as mais diversas linguagens e culturas nas experimentações de aprendizagem em sala de aula, a fim de que a leitura e a escrita sejam ressignificadas a partir das necessidades dos sujeitos e de suas experiências de letramentos digitais, tendo as TIC como interface destas novas formas de relações com o mundo e no mundo, cooperando as TIC como difusoras do conhecimento plural, diverso e multi. Santaella (2008) ressalta que as mídias digitais e os textos digitais são formados por meio das múltiplas linguagens que vão contribuindo com as possibilidades de pensamentos diversos, multi e plural, carregados de implicações sociais, políticas e culturais. Essas linguagens são responsáveis pela forma como nossos sujeitos têm se relacionado.

Neste sentido, toda discussão teórica ajudará nas compreensões e significados do próximo capítulo durante as reflexões e ressignificações dos saberes na análise dos resultados.

\section{ACHADOS: AS EXPERIÊNCIAS DA UTILIZAÇÃO DAS TIC COMO INTERFACE PEDAGÓGICA NA ESCOLA DA EJA}

Certamente, esta é uma das seções mais densas e emblemáticas no sentido de aplicarmos todo conhecimento adquirido para tentar responder a questão, o problema, além de buscar aproximação com as inquietações postas nos objetivos propostos no texto. Estamos cientes de que todos os esforços serão no intuito de atender ao chamado da escola onde, durante as nossas vivências e experiências em seu espaço, os sujeitos demandaram sentidos e significância quanto à possibilidade de contribuição da pesquisa na mudança da práxis, do currículo e na res- 
significação dos saberes dos próprios sujeitos da Educação de Jovens e Adultos.

Toda abordagem metodológica aqui traçada na análise será uma opção política que localizará nosso posicionamento sobre as compreensões, estratégias, organização, rigor, hermenêutica e polissêmica de sentidos descritivos da pesquisa de campo. Imergiremos nas análises das informações coletadas no lócus da pesquisa por meio das entrevistas concedidas pelos alunos e professores, tendo como foco as TIC e as interfaces. A retomada dos conceitos de TIC, Informação e Comunicação são basilares para as análises que faremos nesta categoria e eles aparecem no sentido de sustentar a compreensão das falas dos sujeitos entrevistados.

Cabe aqui construir essa análise trazendo também o conceito de comunicação para o debate, pois a comunicação aqui será evidenciada numa perspectiva comunicacional, a partir do entendimento dos nossos pesquisados, que requereu esta compreensão a partir de Silva (2000) numa ideia de que a comunicação no momento contemporâneo assumiu o lugar não mais da produção e envio da mensagem, mas a comunicação passa a ser vista como a "lógica da comunicação" (p. 136), no sentido de que a mesma assume o lugar de produção, difusão e coautoria de quem a recebe.

Gráfico 1- Saberes das TIC e interfaces coletadas por entrevista (utilização do laboratório de informática pelos alunos)

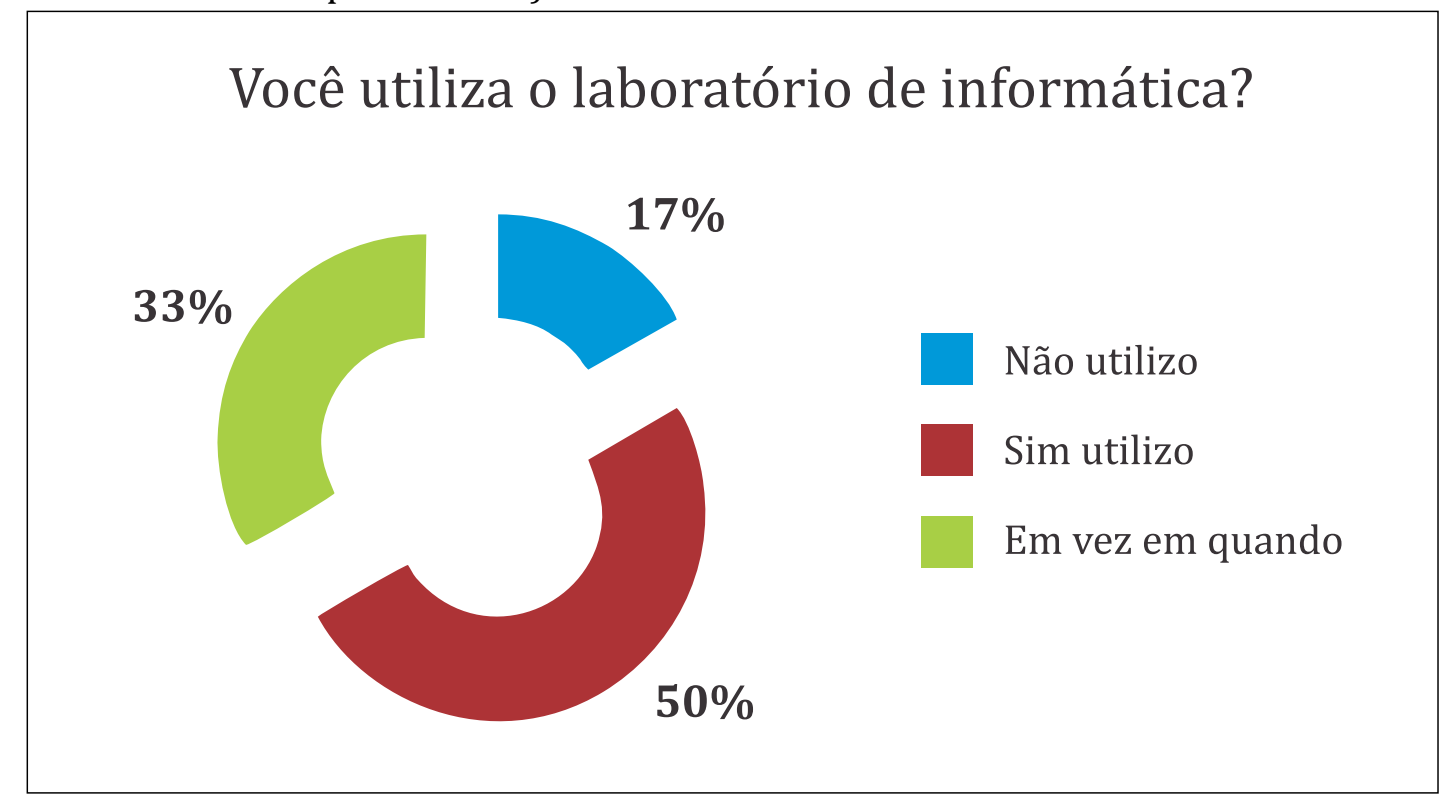

Fonte: Produzido pelos Pesquisadores em 2018, através da coleta das informações do locus.

O laboratório de informática é usado na escola por mais de $50 \%$ dos alunos, é possível visualizar que há uma relação entre os alunos e o laboratório, pois tanto o acesso quanto o uso são demandados pela maioria dos entrevistados, o que nos dá elementos para entender que as TIC não são estranhas e nem distantes deste público, porém, segundo Cox,
Faz-se necessária uma crítica acurada quanto ao uso dos computadores no ambiente escolar, ou fora desse, para que seja possível aproveitar o melhor dessas máquinas sem incorrer no vultoso erro de subestimá-las, desperdiçando recursos ou atribuindo-lhes papéis miraculosos, superestimando-as. Faz-se necessário, portanto, pesquisar (2008, p. 11). 
Assim, não pode haver uso do laboratório de informática, em específico o computador na sala de aula, sem planejamento, reflexão, pesquisa e diálogos críticos, pois correremos o risco da não produção de ressignificação de saberes e nem uma tomada crítica sobre a produção, difusão e uso da informação e comunicação circulante neste dispositivo tecnológico.

Outra informação digna de nota foi no gráfico 1 quando 33\% dos alunos afirmaram utilizar eventualmente o laboratório, o que nos faz refletir sobre algumas possibilidades de questionamento sobre esta frequência: Seria ausência de mediação pedagógica ou tecnológica? Seria falta de tempo? Talvez fosse de interesse? Acreditamos não haver problemas no acesso já que este grupo está dentro dos $80 \%$ que no gráfico 2 afirmaram ter acesso ao laboratório. É preciso entender que isso talvez se deva por que:

[...] a utilização desses meios requer um sujeito ativo, que deve escolher até e como se deveria determinar qual informação utilizar, estabelecer sua ordem e nível de profundidade, possibilitando a formação de novas estratégias cognitivas e novos estilos de expressão e comunicação (LEVY, 2004, p. 16).

Corroboramos com o autor quando ele afirma que não basta ter acesso e utilizar as TIC, são necessárias outras necessidades cognitivas e de um sujeito que assuma uma atitude crítica deste acesso e uso. Podemos aqui inferir que nem sempre acesso significa utilização, pois isso depende de um conjunto de fatores que perpassam desde conhecimentos básicos para acessar o computador, internet e demais programas até o que fazer neste espaço. Cox (2008) nos permite compreender melhor a necessidade de não só ter computador, laboratório, tecnologias digitais para uso educacional, mas é preciso estar preparado para esse uso, tendo uma compreensão bastante definida dos primei- ros passos para esse uso. A citação abaixo pode nos ajudar a desvelar o primeiro fio destes fatores que podem contribuir para um uso esporádico ou não destas TIC:

Assim, pode-se afirmar que há escolas com laboratórios munidos dos mais diversos equipamentos computacionais, em pleno funcionamento, e com os mais "ousados" projetos de crescimento contínuo, há as que ensaiam seus primeiros passos e as que já estão em fase de teste e manutenção do processo de uso dos computadores na educação. No entanto, a maioria das escolas públicas brasileiras enquadra-se como ambientes escolares absolutamente desprovidos de qualquer recurso computacional. Dessa forma, é possível concluir que são e serão por muito tempo numerosas as unidades escolares carentes de estudos, como este, sobre passos iniciais do processo de implantação da informática na educação (COX, 2008, p. 18).

Fica entendido com a citação acima que é fundamental não só ter os aparatos tecnológicos, mas pesquisa, reflexão, planejamento e ação.

A análise a seguir será feita a partir dos gráficos 2 e 3. É importante ressaltar, para que o leitor compreenda que os dois gráficos ilustrativos devem ser analisados conjuntamente, pois um é complemento do outro, isso por que ao entrevistarmos os sujeitos foi feito uma pergunta com duas questões contínuas e complementares. Trouxemos em gráficos separados as questões para facilitar quem analisa as informações, melhor visualização.

Mais da metade dos alunos entrevistados afirmaram que os professores não utilizam o laboratório de informática em suas aulas. Com essa afirmativa, verificamos que os docentes ainda não perceberam que as TIC podem ser aliadas e importantes ferramentas para os seus fazeres pedagógicos e, portanto, não aproveitam o uso laboratório de informática em suas aulas. 
Gráfico 2- Saberes das TIC e interfaces coletadas por entrevista (utilidade do laboratório de informática pelos professores)

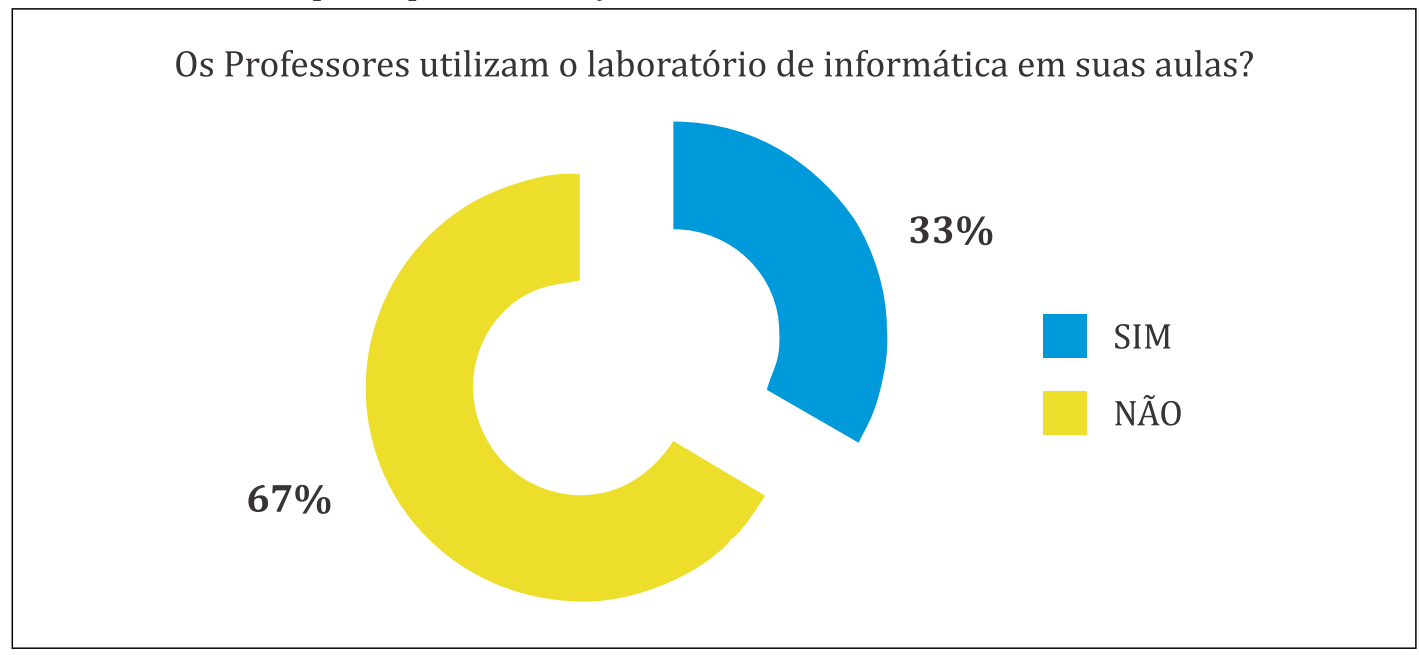

Fonte: Produzido pelos Pesquisadores em 2018, através da coleta das informações do locús.

Ao dialogarmos com a citação acima de Cox e os resultados apresentado no gráfico 2 , reafirmamos uma preocupação quanto ao uso e finalidade das TIC nas salas de aula. Não se pode deixar de fazer uso e inserir as TIC nas classes de EJA, acompanhadas de processo formativo continuado e planejamentos pedagógicos significativos, pois devemos usar e usar bem as TIC, a fim de que as elas possam contribuir com os nossos alunos e assim possam ressignificar seus saberes, bem como produzir, difundir e consumir informação tendo as TIC como interface.

É fundamental deixar claro que o objetivo aqui é mostrar as contradições e incompreensões de ponto vista quanto ao uso do laboratório de informática e sua frequência, e quanto ao uso por parte dos professores na visão dos alunos, e dos próprios professores. Isso porque os professores durante suas entrevistas afirmaram usar o laboratório em suas aulas, mas não é esta a compreensão dos alunos, representada aqui pelos gráficos. Tentaremos ponderar com cuidados e rigores, pois não buscaremos negar nenhum dos sujeitos quanto as suas práticas discursivas em expressar as suas visões da realidade.
Nas incursões das análises dos gráficos acima é curioso o fato dos alunos, em sua maioria, afirmarem que os professores não usavam o laboratório de informática nas aulas e os que afirmaram que os professores usavam, relataram que a frequência acontecia com certa eventualidade.

Como afirmamos anteriormente, esta discussão não é um processo de culpados e inocentes, mas de evidenciar necessidades apontadas a partir das falas dos sujeitos por meio da entrevista. Para compreendermos o papel dos professores no uso do laboratório e das TIC na escola, e nas aulas, Cox (2008, p. 75) pondera que:

O professor é peça-chave na estrutura de transformação da escola desencadeada pelos questionamentos levantados no estudo de inserção das maquinas de processar no ambiente escolar, pois é o fomentador natural da mudança na prática educacional, principalmente, em virtude de seu papel mediador entre alunos e administradores.

E para fomentar mudanças o professor precisa rever suas posturas, reavaliar seus propósitos, remodelar as ferramentas; a docente pressa reestrutura-se, o que requer estudo, análise e esforço; em umas palavras: preparação. 
Nesta perspectiva, o exercício da experiementação da práxis, ação-reflexão-ação de forma dialogada consigo, com os seus alunos e os seus pares sobre a temática TIC, vai permitir ao professor uma retroalimentação formativa que permite atender aos apelos do chão da sala de aula, mas também é necessário, a partir da experiência de si, uma mudança da sua prática pedagógica, avançando na sua postura, pois "a implantação dos computadores na educação demandará necessidades de leitura e interpretação, exigirá, portanto, que o professor apresente disposição para estudar. E para tanto precisa dispor de tempo livre, fora da sala de aula" (COX, 2008, p. 108).

Alguns elementos curiosos e contraditórios apareceram nas falas tantos dos alunos quanto dos professores descritos logo abaixo, onde obtivemos as respostas a partir das seguintes questões: Você realiza atividades de leitura e escrita no laboratório de informática? E que tipo de atividade você realiza no laboratório?

De acordo o tema que foi abordado nós já passamos filmes, e daí comentamos (P.F).

É eu já trabalhei com textos no ambiente virtual, leitura de textos, destacavam algumas palavras ou alguns questionamentos que eram feitos. Muitas vezes tinham um texto, onde eles faziam leituras, e aí de acordo ao que fossem questionados, fossem pedidos eles iram destacando no texto, no próprio computador, utilizam das ferramentas de destacar mesmo, palavra, aí eles iam destacando algumas palavras (P.M).

Bom, é para fazer a adaptação de uma leitura, usando a tecnologia, a gente muitas vezes usamos recursos que eles já possuem que às vezes é celular, tablet. Ausente isso, sendo dentro de um laboratório agente pode fazer o que? Pesquisas de determinados textos, ou então é alimentar esse laboratório com as atividades que eles praticariam geralmente no caderno, quadro e lousa fugindo dessa concepção básica, usariam o que a própria tecnologia que eles já gostam atualmente que é o mundo deles para eles estarem fazendo essa leitura, respondendo questões e atividades usando computadores, tablets ou celulares e com isso possam fazer utilizando a própria internet para fazer as pesquisas ajudando nestes trabalhos (P.T).

Não utilizo mais o laboratório, mas quando utilizava as atividades de leitura e escrita que envolvia minha disciplina que é geografia. Pedia e auxiliava os alunos a realizar pesquisa na internet, após a apresentação do tema da aula e em seguida os alunos apresentavam o conteúdo e a pesquisa. Hoje se eu fosse realizar atividades no computador eu iria trabalhar com a construção de hipertextos e troca de e-mails (P.D).

Percebemos uma discrepância entre as falas dos alunos e as falas dos professores. Pois para $67 \%$ dos alunos os professores não utilizam o laboratório em suas aulas, já os professores afirmaram utilizar, com exceção de uma professora que disse não usar mais. Estas informações permitiram levantar alguns questionamentos que não temos a intenção de responder, mas refletir sobre: Será que há uma incompreensão por parte dos alunos e professores entre a aula com uso das TIC e aula no laboratório de informática? Será que as aulas que os (as) professores (as) desenvolvem no laboratório de informática, os alunos não reconhecem como aula, devido à metodologia, didática e proposta pedagógica desenvolvida? Para Cox: "[...] o docente precisa reestruturar-se, o que requer estudo, análise e esforço; em uma palavra: preparação" (2008, p. 75). Neste sentido, reafirmamos que se faz necessário não só o planejamento no uso da TIC nas aulas, mas é fundamental que os docentes busquem a autoformação e a formação continuada para ter subsídios e poder construir estratégias de ensino que garantam aprendizagens de significados, possibilitando aos 
alunos reconhecerem a finalidade do uso das TIC para as suas aprendizagens.

Conseguimos emergir deste processo compreendendo que o trabalho pedagógico na EJA no laboratório de informática precisa ser construído de forma dialógica e participativa possibilitando aos seus sujeitos elaborarem o desenho pedagógico do processo formativo que possa construir nos alunos uma relação de pertencimento com o trabalho formativo no laboratório.

Reafirmamos o entendimento que é fundamental para qualquer trabalho pedagógico, principalmente os que envolvem leitura e escrita no laboratório de informática, a intencionalidade dialogada com os sujeitos envolvidos, uma mudança na postura formativa, pois não bastar saber usar pedagogicamente o espaço como instrumento das práticas experienciais dos docentes, é necessário mudar as posturas construídas muitas vezes em seus processos de formação ao longo de suas vidas acadêmica e profissional por tendências pedagógicas conservadoras e liberais. Freire nos diz que: "Ninguém caminha sem aprender a caminhar, sem aprender a fazer o caminho caminhando, refazendo e retocando o sonho pelo qual sepôs a caminhar" (1992, p. 79).
Será no laboratório de informática o próprio processo de retroalimentação formativa dos professores.

0 uso do computador como interface na aprendizagem nas novas formas de ler e escrever, além de ressignificar outros saberes, só é possível, segundo Chartier, por que: "[...] essa revolução, fundada sobre a ruptura da continuidade e sobre a necessidade de aprendizagens radicalmente novas, e, por tanto um distanciamento com relação aos hábitos, tem muito poucos precedentes tão violentos na longa história da cultura escrita" (1998, p. 93).

Apesar dos problemas de aprendizagem com o uso das TIC serem marcas fortes, apresentadas no projeto de intervenção, percebeu - se nas experiências com as TIC que eles possuem saberes diferentes no que diz respeito ao uso das tecnologias digitais, quanto a: digitação, ligar e desligar o computador, utilizar o editor de apresentação, colar e copiar. Neste sentido, Freire nos corrobora afirmando que, "[...] não há saber mais, nem saber menos, há saberes diferentes" (1987, p. 68). Logo é possível que eles saibam usar o smartphone, mas não o computador ou até mesmo realizar uma atividade de produção de slides.

Gráfico 3 - Saberes da experiência coletadas nas entrevistas (atividade no laboratório de informática)

Quais atividades você realiza no laboratório de informática?

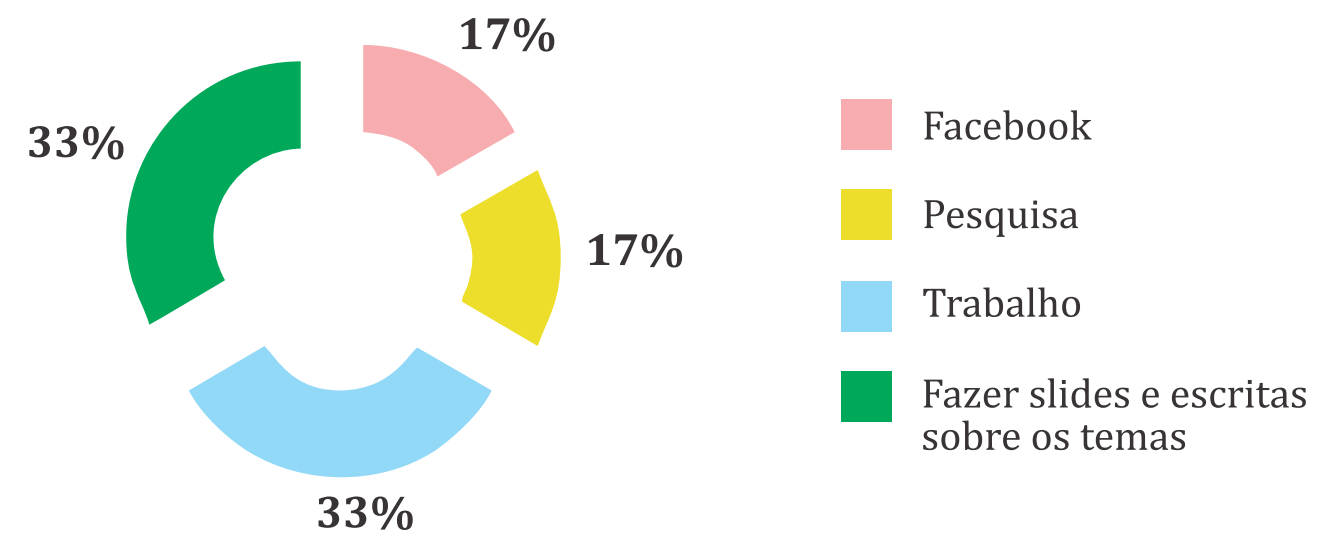

Fonte: Produzido pelos Pesquisadores em 2018, através da coleta das informações. 
É extremamente importante compreendermos que os saberes são representados por relações e construções adquiridas ao longo da trajetória dos sujeitos, tendo como base destas construções, as experiências sociais e individuais que são ressignificadas ao longo das vivências. Deste modo, evidenciaremos abaixo as compreensões dos saberes por parte dos alunos representados no gráfico $\mathrm{n}^{-0}$, nas transcrições de suas falas. Para a maioria dos entrevistados as relações de atividades que fazem no laboratório estão totalmente relacionadas com práticas de escrita, pois tanto o "trabalho" como citaram quanto "fazer slides e escritas sobre os temas" tem essa finalidade ativa com as práticas de escrita. Os outros 44\% apesar de responderem que utilizam para uso do "facebook" e de "pesquisa", atividades estas que têm como a primeira ação ativa e direta a leitura, carregam também a possibilidade de escrita. Podemos perceber que essas atividades de escrita e leitura acontecem no laboratório por que "[...] o texto escrito tornou-se multissemiótico, a leitura do texto verbal escrito já não basta mais, ele é constituindo de signos e de outras modalidades de linguagens. A leitura transcende ao texto proporcionando outras sensações sensoriais" (ROJO 2007, p. 7).

Diante do exposto, fica evidente as TIC como possibilidades multissemióticas de ler e escrever dos sujeitos no e com o mundo de forma acadêmica ou não.

\section{CONSIDERAÇÕES PONTUAIS}

Observamos que este artigo possibilitou compreender que as "Experiências outras na utilização das TIC como interface pedagógica na escola de Educação de Jovens e Adultos", da Escola Municipal Lév, no município de Araçás-BA, por apresentarem características e princípios de diálogos, cons- cientização, reconhecimento e validação das experiências de por meio da utilização do laboratório de informática como interfaces pedagógica das TIC.

Cabe aqui, retomarmos os conceitos chaves do texto: EJA, TIC e Letramentos que permearão alguns parágrafos abaixo com um olhar não mais ingênuo, mas uma compreensão provida de elementos das análises e dos sentidos construídos no campo.

Compreendemos a EJA como modalidade de ensino a ser ofertada para aqueles que tiveram seus direitos à escolarização, negados ao longo da sua trajetória de vida, transitada entre a infância e adolescência, bem como na juventude, por meio de demanda econômica, cultural e social. Falamos aqui de negação de direitos e é assim que percebemos o lugar que é ocupado por aqueles que não podem ou não puderam experienciar a escolarização e garantir a educação básica como direito a acessar o conhecimento sistematizado, a leitura e a escrita.

Na EJA, os alunos não podem e nem devem ser tratados como passivos das TIC e sim como expressões da ação do homem sobre os bens na melhoria da qualidade da vida humana, produtor, consumidor e difusor da informação e comunicação. Nesse contexto, seus saberes e experiências são essenciais nas compreensões como indivíduos, para serem ressignificados com o acesso às TIC e às Tecnologias Digitais. Por seu turno, a interface é instrumento das mais diversas ressignificações destas experiências de saberes x TIC entrelaçados por meio das conexões que resultarão em novos saberes e experiências, visto que a interface é o rito de passagem entre sujeito e objeto culminando com o resultado desta passagem.

As experiências de letramentos são construídas a partir das práticas sociais por meio de experiências com a leitura e a escrita, nas 
quais os códigos, símbolos e a tecnologias são elementares nesta construção.

Diante do exposto, ao ressignificarmos os conceitos/categorias para construção epistemológica do artigo, deixaram acessível à compreensão os significados de EJA, TIC, e o letramento. É imprescindível retomarmos o problema da pesquisa: Como utilizar as tecnologias da informação e da comunicação como interface pedagógica para os sujeitos da EJA? A utilização das TIC se deu a partir do uso das TIC, por intermédio das experiências de letramentos tendo como princípio pedagógico, o diálogo, a partir de um tema gerador que ajudou os alunos a não só lerem e escreverem, mas à reflexão crítica e à tomada da consciência da validação e reconhecimento dos seus saberes, através da ressignificação, tendo as TIC como uma interface que possibilitaram a ampliação dos conhecimentos sistematizados, incorporação de novos conhecimentos e reconhecimento de que os saberes são elementares na estruturação cognitiva das suas aprendizagens.

No que se refere ao objetivo geral da pesquisa, isto é, analisar como a utilização das TIC como interface pedagógica contribui com os sujeitos da EJA. Foi alcançado, na mesma perspectiva da implementação do projeto de intervenção realizado na escola que possibilitou, por meio das TIC, através do laboratório de informática e das rodas de conversas, experiências de letramentos cruciais para o processo de conscientização, melhoria da leitura e escrita, além do reconhecimento dos saberes.

Finalizamos, afirmando que a escola precisa repensar, urgentemente, a formação continuada para os professores da EJA, a fim de que eles possam utilizar o laboratório como interface pedagógica, bem como estudos sobre dialogicidade, conscientização, saberes e experiências de si, com a implantação de práticas dialógicas para reconhecer e validar as experiências de saberes.

\section{REFERÊNCIAS}

BRASIL. Plano Nacional de Educação (PNE), Lei no 10.172 de 09 de janeiro de p. 99, 2001.

CHARTIER, Roger. A Aventura do Livro. Tradução de Reginaldo Carmello Correa de Moraes. São Paulo: UNESP, 1998.

COX, KeniaKodel. Informática na Educação Escolar. São Paulo: Autores Associados, 2008.

FREIRE, Paulo.Educação e mudança. 11.ed. Rio de Janeiro: Paz e Terra, 1983.

Pedagogia do Oprimido. 17. ed. Rio de Janeiro: Paz e Terra, 1987.

Educação como prática daliberdade. 23. ed. Rio de Janeiro: Paz e Terra, 1993.

Pedagogia da Autonomia: saberes necessários à prática educativa. 4. ed. São Paulo: Paz e Terra, 1997.p.25- 32.

. Pedagogia da Esperança: um reencontro com a Pedagogia do Oprimido. $4^{\underline{a}}$ ed. Rio de Janeiro: Paz e Terra, 1992.

GADOTTI, Moacir. Pressupostos do Projeto Pedagógico. In: MEC, Anais da Conferência Nacional de Educação para Todos. Brasília, 28/8 a 2/9/1994.

LÉVY, Pierre. Cibercultura. Tradução de Carlos Irineu da Costa. 3. ed. São Paulo: Editora 34, 2004.

LÜDKE, M; ANDRÉ, M. E. D. A. Pesquisa em Educação: abordagens qualitativas. São Paulo: EPU, 1986.

PERREIRA, Marina Lúcia de Carvalho. A construção do letramento na EJA. Belo Horizonte: Autêntica/FCH-FUMEC,2004.

ROJO, Roxane. Letramentos múltiplos, escola e inclusão social. São Paulo: Parábola Editorial, 2009.

Letramentos digitais - a leitura como réplica ativa. Trab. Ling. Aplic., Campinas, 46(1): 63-78, Jan./Jun. 2007. Disponível em: $<$ http>://www.scielo.br/pdf/tla/.../a06v46n1. 
pdf> acesso em 23/12/15.

Multiletramentos na escola. São Paulo: Parábola Editorial, 2012.

SANTAELLA, Lucia. Culturas e artes do pós -humano. São Paulo: Paulus, 2008.

SILVA, Marco. Sala de aula interativa. Rio de Janeiro: Quartet, 2000.

SOUZA, Amilton Alves de. Círculos de Diálogos e Práticas de Letramentos com as TIC: Saberes, Fazeres e Interfaces com a EJA / Amilton
Alves de Souza. - Salvador, 2015. 217f. 973.

REBÊLO, P. Inclusão Digital: o que é e a quem se destina? 2013 http://webinsider.com. br/2005/05/12/inclusao-digital-o-que-e-e-aquem-se-destina/. Acessado em 15 de dezembro de 2015.

YIN, R.K. Estudo de caso: planejamento e métodos. 4. ed. Porto Alegre: Bookman, 2010.

Recebido em: $19 / 02 / 2019$

Aprovado em: 07/05/2019 